\title{
Flora das cangas da Serra dos Carajás, Pará, Brasil: Heliotropiaceae
}

Flora of the canga of Serra dos Carajás, Pará, Brazil: Heliotropiaceae

\author{
Maurício Takashi Coutinho Watanabe $e^{1,2}$ \& Alice Lima Hiura ${ }^{1}$
}

\begin{abstract}
Resumo
É apresentado o levantamento das espécies de Heliotropiaceae para as formações de canga na Serra dos Carajás, Pará, Brasil. Duas espécies foram registradas: Euploca humistrata (que se configura como um novo registro para a flora paraense) e E. lagoensis. São fornecidas descrições morfológicas para as espécies, ilustrações e comentários taxonômicos.

Palavras-chave: Amazônia, Boraginales, FLONA de Carajás, florística, novo registro, taxonomia.
\end{abstract}

\begin{abstract}
This is the account of the species of Heliotropiaceae, which have been reported on the canga of the Serra dos Carajás, state of Pará, Brazil. Only two species were recorded: Euploca humistrata (a new record for Pará state) and E. lagoensis. Descriptions, illustrations and comments are also provided.
\end{abstract}

Key words: Amazon, Boraginales, FLONA de Carajás, floristics, new record, taxonomy.

\section{Heliotropiaceae}

Nas últimos anos, a sistemática de Boraginales tem instigado, discussões a respeito do reconhecimento e do posicionamento de determinadas famílias na ordem (APG IV 2016; BWG 2016). Neste manuscrito, adotaremos o desmembramento de Boraginaceae s.l. em diversas famílias (BWG 2016) com base nos mesmos critérios já apresentados na "Flora das cangas da Serra dos Carajás, Pará, Brasil: Cordiaceae" (Watanabe et al. 2017).

As espécies inclusas em Heliotropiaceae Schrad. podem apresentar hábito variável, desde ervas até árvores. Os ramos apresentam folhas simples e alternas. As flores são pentâmeras, geralmente bissexuadas, solitárias ou arranjadas em inflorescências terminais ou axilares, em tirso ou escorpioides. As sinapomorfias da família são a presença de um estilete terminal com uma cabeça estigmática cônica e o estigma basal em forma de anel. O gineceu quase sempre apresenta um disco nectarífero na base do ovário. $\mathrm{O}$ fruto pode ser carnoso ou seco, geralmente com 4 sementes (ou raramente 1-2 sementes) (BWG 2016).

Heliotropiaceae é constituída por quatro gêneros: Euploca Nutt. (ca. 100 spp.), Heliotropium
L. (325 spp.) Myriopus Small (25 spp.) e o monotípico Ixorhea Fenzl (endêmico da Argentina) totalizando cerca de 450 espécies (BWG 2016). A família possui ampla distribuição, embora esteja concentrada principalmente nas regiões tropicais e subtropicais (BWG 2016). No Brasil, ocorre em todos os estados e está representada por todos os gêneros, com exceção de Ixorhea (BFG 2015). Nas cangas da Serra dos Carajás, foi registrado somente o gênero Euploca, com duas espécies: E. humistrata (Cham.) J.I.M.Melo \& Semir e E. lagoensis (Warm.) Diane \& Hilger.

\section{Euploca Nutt.}

As espécies de Euploca apresentam hábito herbáceo ou arbustivo, geralmente com frutos secos (Feuillet 2016). As flores bissexuadas são arranjadas em inflorescências escorpioides ou menos frequentemente solitárias (Melo \& Semir 2010). Os estames são adnatos ao tubo da corola, com anteras apresentando ápice piloso; gineceu com estigma séssil com forma variada (Melo 2017). As espécies do gênero são morfologicamente semelhantes às de Heliotropium, mas diferem pelas inflorescências bracteadas (exceção observada em Heliotropium

\footnotetext{
Instituto Tecnológico Vale, R. Boaventura da Silva 955, Nazaré, 66055-090, Belém, PA, Brasil.

${ }^{2}$ Autor para correspondência: mtcwatanabe@gmail.com
} 
sect. Ebracteata), anatomia foliar com estrutura Kranz, frutos com quatro núculas e embrião curvo (Hilger \& Diane 2003; Melo \& Semir 2009), esta última característica é compartilhada com as espécies de Myriopus Small, gênero neotropical (Melo, comunicação pessoal).
O gênero possui cerca de 100 espécies (Melo \& Semir 2010), distribuídas nas regiões tropicais, subtropicais e temperadas (Melo \& Semir 2009). No Brasil são referidas 17 espécies que ocorrem nos mais diversificados domínios fitogeográficos e em todos os estados, com exceção do Espírito Santo (BFG 2015).

\section{Chave de identificação das espécies de Euploca das cangas da Serra dos Carajás}

1. Ramos vilosos, até $11 \mathrm{~cm}$ compr.; pedicelo até $2 \mathrm{~mm}$ compr.; corola tubular, lobos oblongos a largoespatulados, ápice mucronulado 1.1. Euploca humistrata

1'. Ramos pubérulos, 19-45 cm compr.; pedicelo 4-9 mm compr; corola campanulada, lobos elípticos a oblongos, ápice arredondado-cuspidado. 1.2. Euploca lagoensis

1.1. Euploca humistrata (Cham.) J.I.M.Melo \& Semir, Kew Bull. 64(2): 288. $2009 . \quad$ Fig. 1a-c Erva prostrada. Ramos até $11 \mathrm{~cm}$ compr., vilosos. Lâmina foliar 3-7 × 1-2 mm, cartácea, elíptica, ápice agudo a arredondado, margem revoluta, setosa em ambas as faces; pecíolo ca. $1 \mathrm{~mm}$ compr., piloso. Flores solitárias, supra-axilares; pedicelo 0,75$1,70 \mathrm{~mm}$ compr., glabro a esparsamente piloso; cálice esverdeado, 2,2-3 mm compr., esparsamente piloso, lacínios elíptico a lanceolado, ápice agudo; corola 3,2-3,7 mm, tubulosa, constrita na porção basalmediana, tubo amarelo, lobos alvos, oblongos a largoespatulados, ápice mucronulado, margem levemente revoluta, sem apêndices; estames subsésseis; ovário $0,9-1 \times$ ca. $0,6 \mathrm{~mm}$, globoso, glabro; estigma $0,1-0,2$ $\mathrm{mm}$ compr., glabro. Fruto esquizocarpo, 1,5-1,8 mm diâm., globoso a subgloboso, cálice persistente.

Material selecionado: Canaã do Carajás, Serra da Bocaina, 25.VI.2015, bot. e fl., N.F.O. Mota et al. 3425 (MG).

Euploca humistrata se distingue de E. lagoensis, principalmente pelos comprimentos dos ramos vegetativos mais curtos, com até $11 \mathrm{~cm}$ compr. (vs. 19-45 cm compr.), dos pedicelos florais não ultrapassando os $2 \mathrm{~mm}$ compr. (vs. 4-9 mm compr.), da corola tubular (vs. campanulada), com os lobos oblongos a largo-espatulados (vs. elípticos a oblongos), e ovário com $0,9-1 \mathrm{~mm}$ de comprimento (vs. $0,4-0,5 \mathrm{~mm}$ ).

Distribui-se na América do Sul: Brasil, Guiana e Venezuela (Feuillet 2016). No Brasil havia registro somente para os estados de Goiás e Minas Gerais, principalmente em áreas de cerrado lato sensu (BFG 2015). Desta maneira, este é o primeiro registro da espécie para o estado do Pará, onde foi encontrada nas áreas de canga da Serra dos Carajás, mais precisamente em lagoas temporárias da Serra da Bocaina, localizada no recém criado Parque Nacional dos Campos Ferruginosos.
1.2. Euploca lagoensis (Warm.) Diane \& Hilger, Bot. Jahrb. Syst. 125(1): 48. $2003 . \quad$ Fig. 1d-f Erva ereta. Ramos $19-45 \mathrm{~cm}$ compr., pubérulos. Lâmina foliar 0,7-1,2 ×0,2 cm, carnosa, estreito-elíptica a oblanceolada, ápice agudo, base aguda a atenuada, margem inteira, glabra; pecíolo 0,8-1 mm compr., pubérulo. Flores solitárias, supra-axilares; pedicelo 4-9 mm compr., glabro a pubérulo; cálice 2-3 mm compr., glabro, lacínios lanceolados, ápice agudo; corola 3-3,5 mm, campanulada, tubo amarelo, lobos alvos, elípticos a oblongos, ápice arredondado a cuspidado, margem revoluta, sem apêndices; estames sésseis; ovário 0,4-0,5 $\times 0,5 \mathrm{~mm}$, subgloboso, glabro; estigma 0,1-0,2 mm compr., glabro; fruto esquizocarpo, 1,6-1,8 mm diâm., piriforme, cálice persistente.

Material selecionado: Canaã dos Carajás, Serra do Rabo, buritiranal, 16.XII.2010, fl., N.F.O. Mota et al. 1903 (MG). Parauapebas, FLONA de Carajás, N5, Trilha da Lagoa da Mata, 04.XII.2015, fl. e fr., M.F.L. Almeida et al. 37 (MG).

Euploca lagoensis é diferenciada das demais espécies do gênero, especialmente as que possuem flores solitárias e tubo da corola amarelo e lacínios alvos, como em E. humistrata, por um conjunto de características, tais como os ramos pubérulos, as flores longamente pediceladas, supra-axilares e ausência de apêndices entre os lacínios da corola. Ocorre no México, América Central, Suriname, Guiana Francesa, Venezuela e Brasil (Feuillet 2012, 2016). No Brasil há registros para a região Norte (Amazonas e Pará), Nordeste (Ceará, Paraíba, Piauí e Rio Grande do Norte), Centro-Oeste (Goiás e Mato Grosso do Sul) e Sudeste (Minas Gerais e São Paulo), associada a vegetações de Caatinga stricto sensu, Cerrado lato sensu, Floresta de Várzea e Savana Amazônica (BFG 2015). Na Serra dos Carajás foi registrada em lagoas temporárias de 

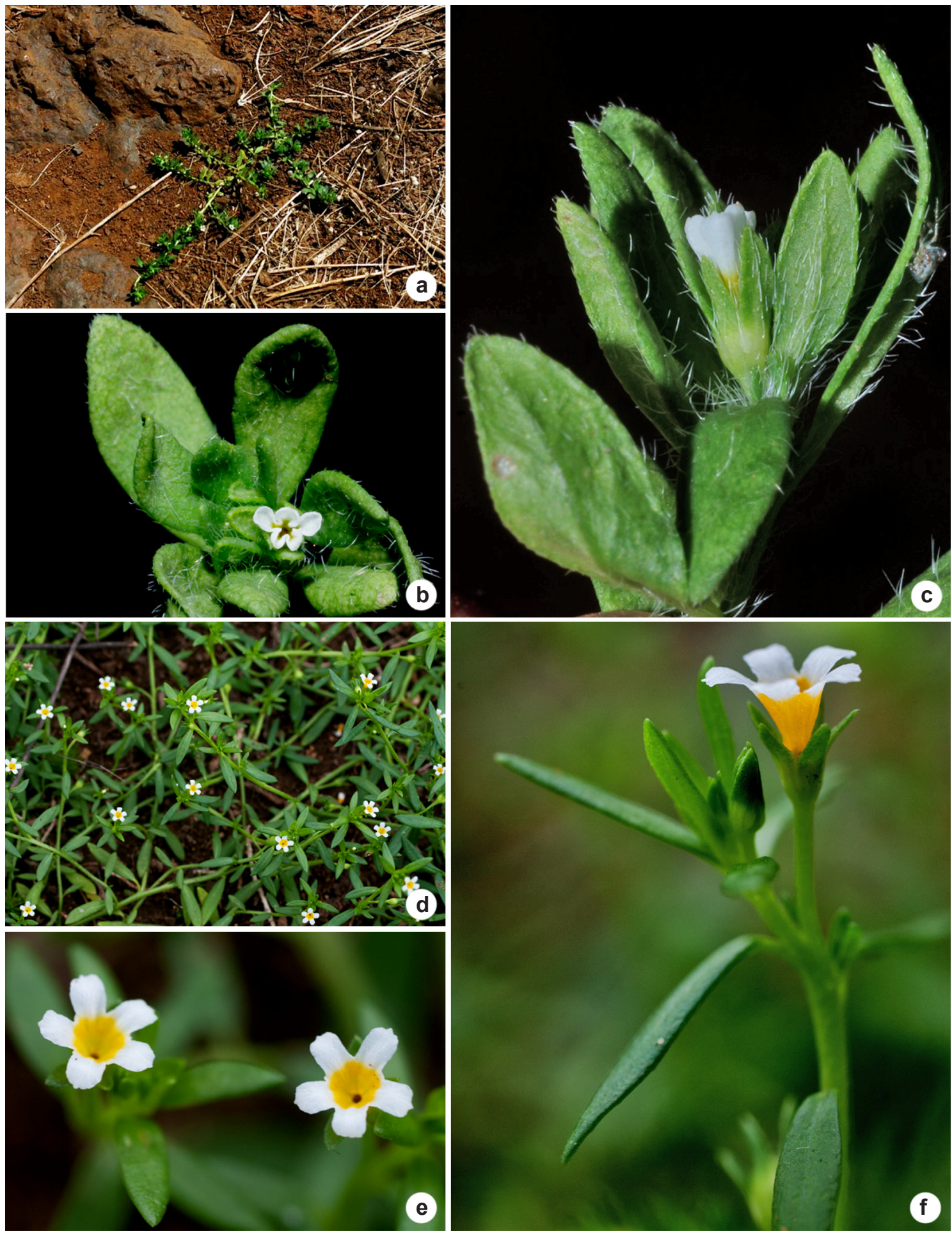

Figura 1 - a-c. Euploca humistrata - a. hábito; b. vista frontal da flor; c. hábito evidenciando a vista lateral da flor. d-f. Euploca lagoensis - d. população; e. vista frontal da flor; f. hábito evidenciando a vista lateral da flor. Fotos: a. Maurício Watanabe; b-c. Nara Mota; d-f. Pedro Viana.

Figure 1 - a-c. Euploca humistrata - a. habit; b. frontal view of the flower; c. habit showing lateral view of the flower. d-f. -Euploca lagoensis - d. population; e. frontal view of the flower; f. habit showing lateral view of the flower. Photos: a. Maurício Watanabe; b-c. Nara Mota; d-f. Pedro Viana. 
canga, tanto na trilha da mata da Flona de Carajás (N5) como na Serra do Rabo (porção da Serra da Bocaína), incluída no Parque Nacional dos Campos Ferruginosos.

\section{Agradecimentos}

Agradecemos ao Instituto Tecnológico Vale e ao Museu Paraense Emílio Goeldi, a estrutura fornecida para realização deste trabalho. À curadoria do herbário MG, a disponibilidade dos materiais examinados. À Nara Mota e Pedro Viana pelas fotografias cedidas. Ao projeto objeto do convênio MPEG/ITV/FADESP (01205.000250/2014-10) e ao projeto aprovado pelo CNPq (455505/2014-4), o financiamento.

\section{Referências}

APG IV (2016) An update of the Angiosperm Phylogeny Group classification for the orders and families of flowering plants: APG IV. Bot. J. Linn. Soc. 181: 1-20.

BFG - The Brazil Flora Group (2015) Growing knowledge: an overview of seed plant diversity in Brazil. Rodriguésia 66: 1085-1113.
BWG - Boraginales Working Group (2016) Familial classification of the Boraginales. Taxon 63: 502-522.

Feuillet C (2012) Boraginaceae. In: Acevedo-Rodríguez P \& Strong MT (eds.) Catalogue of seed plants of the West Indies. Smithsonian Institution Scholarly Press, Washington. Pp. 157-174.

Feuillet C (2016) Two new combinations in Euploca Nutt. (Heliotropiaceae, Boraginales) and a conspectus of the species of the Guiana Shield area. Phytokeys 61: 101-124.

Hilger HH \& Diane N (2003) A systematic analysis of Heliotropiaceae (Boraginales) based on the trnL and ITS1 sequence data. Botanische Jahrbücher für Systematik 125: 19-51.

Melo JIM \& Semir J (2009) Two new brazilian species and new combinations in Euploca (Heliotropiaceae). Kew Bulletin 64: 285-289.

Melo JIM \& Semir J (2010) Taxonomia do gênero Euploca Nutt. (Heliotropiaceae) no Brasil. Acta Botanica Brasilica 24: 111-132.

Melo JIM (2017) Nuevas combinaciones en Euploca (Heliotropiaceae) de México. Revista Mexicana de Biodiversidad 88: 759-760.

Watanabe MTC, Hiura AL \& Nogueira MCN (2017) Flora das cangas da Serra dos Carajás, Pará, Brasil: Cordiaceae. Rodriguésia 68: 955-960.

Lista de exsicatas

Almeida MFL 37 (1.2). Mota NFO 1903 (1.2), 3425 (1.1). Watanabe MTC 432 (1.1). 